\title{
Envisioning the Health Research System in the Philippines by 2040: A Perspective Inspired By AmBisyon Natin 2040
} \author{
Teddy S. Dizon ${ }^{1}$ and Eva Maria Cutiongco-de la Paz ${ }^{2}$ \\ ${ }^{1}$ Alliance for Improving Health Outcomes \\ ${ }^{2}$ National Institutes of Health, University of the Philippines Manila
}

Jaifred Christian F. Lopez, ${ }^{1}$ Chiqui M. de Veyra, ${ }^{1}$ Lester Sam A. Geroy, ${ }^{1}$ Reneepearl Kim P. Sales, ${ }^{1}$

\begin{abstract}
Background and Objective. This paper aims to describe long-term visions for health research in the Philippines. Ambisyon Natin 2040, an overarching vision for a dynamic country by the year 2040, is its main inspiration as this enables innovation and sustainable development.

Methods. The health research profile conceptual framework developed by Tugwell et al., (2006) was utilized to structure the articulation of these visions. Review of related literature, reports, and documents and in-depth interviews with key players in health research were conducted.

Results. In view of economic and technological developments in the country, it is expected that in 2040, health research priorities shall be more trans-disciplinary and more advanced. Research on health regulation and ethics will continue to be of importance. A more enabling environment for health research is also envisioned, since majority of research funding is expected to come from government, in addition to more research-friendly laws. More innovative platforms will be utilized to disseminate research results. The increasing international exposure and impact of academic work in the Philippines is also envisaged.

Conclusion and Recommendations. Health research in the Philippines has been benefitted by a lot of gains and advances in the past years. Thus, to create an enabling health research system in the Philippines by 2040 , focusing on innovations in health research, increased number of funding sources, and crafting of better policies on health research should be pursued. Sustaining these gains and advancing health research in our country entail collective effort from different stakeholders, both public and private.
\end{abstract}

Key Words: health research visions, Philippine health research, health research priorities, resources for health research, health research production, health research packaging, health research impact

\section{INTRODUCTION}

Corresponding author: Teddy S. Dizon, RN, DIH Alliance for Improving Health Outcomes 62 West Avenue, Quezon City 1104, Philippines Telephone: +639173082178

Email: tsdizon1@up.edu.ph
In 2015, the Philippines reached the 100-million population mark $(100,981,437), 8.64$ million more than the country's recorded population in 2010 . The country is expected to reach the projected total population of more than 142 million by 2045. ${ }^{1}$ In anticipation of the needs of the country's growing population, the National Economic and Development Authority (NEDA) developed Ambisyon Natin 2040, a set of visionary statements to guide and serve as the anchor of the country's plan for the next 22 years. Ambisyon Natin 2040 represents the collective long-term vision and aspirations of the Filipino people for themselves and for the Philippines by 2040. 
As articulated in the document, the Philippines is envisioned to be a prosperous middle-class society where "no one is poor, people live long and healthy lives, and are smart and innovative, which underline the importance of developing new approaches to improve the Filipino way of life." The NEDA itself affirms that these aspirations are borne out of having 1 ) healthy lifestyle choices; 2) safer and cleaner products and processes; 3 ) products that promote good health; 4) policies that promote work-life balance; and $5)$ access to affordable and good quality healthcare. ${ }^{1}$

It has been demonstrated that sustained progress in achieving these visions is primarily driven by research and innovation ${ }^{2}$ given its crucial role in providing evidence that influence policy decisions to shape the health sector. In other countries, research has been shown to have an enormous impact on human health and longevity, and that the resulting increased productivity of the population contributes greatly to the national economy., 4, 5 More importantly, a vibrant research and development sector can contribute powerfully to the country's sustainable development, which is defined as development that meets the needs of the present, without compromising the ability of future generations to meet their own needs. ${ }^{6}$ It recognizes that growth must be both inclusive and environmentally sound to reduce poverty and build shared prosperity for today's population, and to continue to meet the needs of future generations. ${ }^{7}$

Setting a long-term vision for health research will therefore be crucial to set the direction of health research in the country in support of the Ambisyon Natin 2040 and achieve sustainable development in the country at large. This paper aimed to describe long-term visions of key policymakers and decision makers for health research in the Philippines by 2040 .

\section{MATERIALS AND METHODS}

To identify possible directions for health research while relating them to the currently existing health research system components, we reviewed related literature, reports, and documents from the Department of Health (DOH) and Department of Science and Technology (DOST). We also conducted in-depth interviews with key players in health research from DOH, World Health Organization Philippines, University of the Philippines Manila - National Institutes of Health (UPM-NIH), Philippine Council for Health Research and Development (PCHRD), Philippine National Health Research System (PNHRS), Commission on Higher Education (CHED), and academe using a semistructured interview tool. Interviews were audio recorded, transcribed, and coded using Microsoft Excel. Content thematic approach was utilized in analyzing the verbal data. ${ }^{8}$ To familiarize and identify emerging themes and subthemes, the authors read at least twice all transcribed data and notes. Sub-group analysis was done by examining themes and subthemes among interviews. Interpretative analysis on the responses and what may have been inferred or implied was also done. ${ }^{8}$

In analyzing the gathered data, the authors grouped the themes and subthemes using the health research profile conceptual framework developed by Tugwell et al. to assess health research systems in low- and middle-income countries. ${ }^{9}$ This conceptual framework characterizes health research system using five linked components namely, health research priorities, resources, production, packaging, and impact (Figure 1).

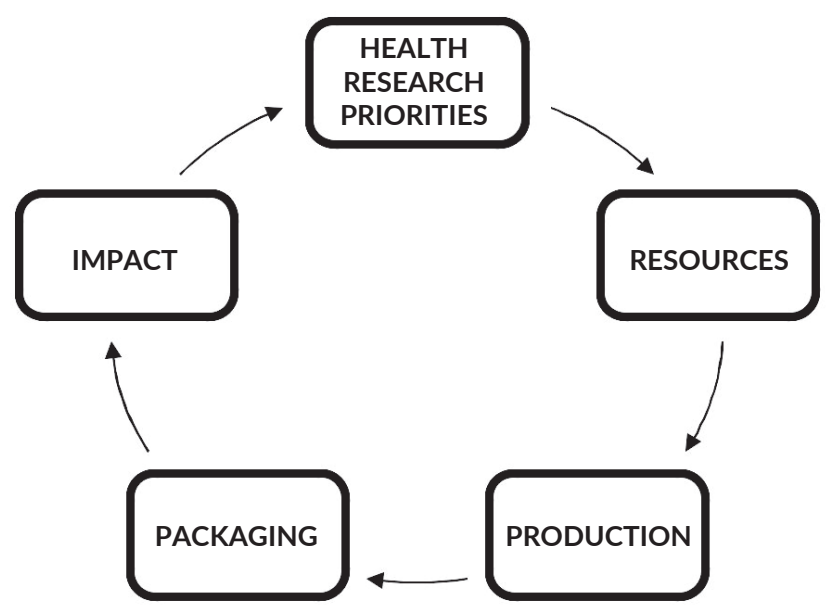

Figure 1. Health Research Profile Conceptual Framework adopted from Tugwell et al., (2006).

In this framework, health research priorities refer to a list of topics that serve as guide to produce the most costeffective investment in knowledge production that is relevant to the local context. Resources refer to financial, human and institutional capacities, infrastructure, and research environment necessary to sustain an effective health research system. Human capacities include not only the supply of knowledge, but also the demand for knowledge to enhance equity in health for development. Production refers to the capacity of the research systems to produce relevant output for policymaking such as whether research is produced in time to be useful to policymaking. Packaging refers to the synthesis of knowledge in appropriate language and formats for different intended audiences (e.g. publications for researchers, lay summaries for policy-makers in governments, and research forums and networks for civil society) involved in policy and social processes leading to optimal health action and health equity. Packaging is essential to encourage the uptake and translation of research into improved health of the population. Impact refers to evidence that knowledge from the research is used. ${ }^{9}$

\section{Ethical considerations}

The study protocol was reviewed and approved by St. Cabrini Medical Center - Asian Eye Institute Ethics Review Committee. Individual informed consent was obtained from each interviewee prior to the interviews. Privacy 
and confidentiality were also ensured through selection of appropriate venue. Only authorized personnel from the research team were allowed access to the results to guarantee the anonymity of study participants and the confidentiality of information gathered.

\section{RESULTS}

Envisioning health research in the Philippines through the development of this paper allowed for scoping of various factors affecting the heath research system, and generated ideas and recommendations from key players in health research. This section includes available data pertaining to the five identified components of health research, as well as the visions and insights gathered from the interviews. Succeeding sections of the paper present the data gathered for each health research system component.

\section{Health research priorities}

To maximize resources allocated for health research, it is essential that researches conducted are based on a rational priority setting process. ${ }^{10}$ In the Philippines, the PNHRS developed the National Unified Health Research Agenda (NUHRA) which outlines the areas and topics that needs to be addressed in the Philippines for the next five years. To date, three versions of NUHRA have been developed. Table 1 shows the list of priority topics for each NUHRA. The development of the NUHRA facilitated integration of health research priorities of the four core agencies of the PNHRS: $\mathrm{DOH}, \mathrm{PCHRD}, \mathrm{CHED}$, and UPM-NIH.

In 2040, health research priorities are envisioned to be more trans-disciplinary. While it should respond to current needs and problems of the country, more advanced researches, particularly on telemedicine, space medicine, biomarkers, and other technology-based researches, will also be conducted. Researches on health regulation and ethics will continue to be of importance as well.

\section{Resources}

In 2007, the Philippines' investment in research and development was approximately USD 340 million, which accounted for $0.11 \%$ of the GDP. This continued until 2013 where a subtle increase of $0.02 \%$ was seen in research and development investment, accounting for $0.13 \%$ of the country's GDP. ${ }^{11,12}$ Investment in research and development of private organizations, government agencies, and higher education institutions (HEIs) accounted for 66\%, 26\%, and $6 \%$, respectively. In programs, private organizations, government agencies, and HEIs accounted for 57\%, 18\%, and $23 \%$, respectively. While private organizations have the highest investment in research and development, investment from the public sector in terms of budget and activities has been in an upward trend in the recent years. ${ }^{13}$

Figure 2 shows the research and development budget of the government, DOST, CHED, and DOH in 2011 and 2015. Government allocation for research and development has grown from P7.9B in 2011 to P11.7B in 2015, a marked increase of 49\%. DOST had the highest budget of P1.433B in 2011 to P3.802B in 2015, an increase of $16.2 \%$. Similarly, CHED had an increase from P748M in 2011 to P2.090B in 2015. DOH, on the other hand, had a budget of less than P50M for each year of 2011 until 2013 before this was increased to P1.344B in 2014. Currently, the regional offices of the $\mathrm{DOH}$ allocates $2 \%$ of its total budget for research. The UP System allocated a separate budget for research in 2014 and 2015 with P539M and P544M, respectively, compared to previous years where research funding was shared with other activities such as extension services. ${ }^{14}$ UPM-NIH has also seen an increase in funding from approximately $\mathrm{P} 2 \mathrm{M}$ in the 1990s to approximately P5M in 2000s. Further increase to $\mathrm{P} 10 \mathrm{M}$ is currently being proposed. ${ }^{15}$

Meanwhile, regarding human resources, in 2007, the number of researchers in the Philippines was 11,490 head count (HC) and 6,957 full time equivalent (FTE). ${ }^{13}$ An increase in the number of researchers was seen in 2011 and 2013 with 14,170 HC and 8,038 FTE in 2011, and 26,625 $\mathrm{HC}$ and 18,481 FTE in 2013. ${ }^{11,12}$ Figure 3 shows the number of researchers in the Philippines in 2007, 2011, and 2013. Looking at the number of researchers per 1,000 labor force, the size of research human resource in the Philippines is 0.32 researchers $\mathrm{HC}$ and $0.19 \mathrm{FTE}$. The Philippines ranks fifth among ASEAN countries in number of researchers. ${ }^{13}$ However, health researchers remain concentrated in the National Capital Region, where majority of academic institutions, medical and research centers, and research mentors are located. Importantly, a large number of health research being done are in the clinical sciences due to the predominance of researchers with medical degrees, in contrast to the health social sciences, basic sciences and advanced sciences like biotechnology. ${ }^{16}$ This is further supported by the development of the clinician-scientist as an emerging career niche. ${ }^{17}$

Table 1. Priority topics for each NUHRA

\begin{tabular}{|c|c|c|}
\hline NUHRA 1 (2006-2010) & NUHRA 2 (2011-2016) & NUHRA 3 (2017-2022) \\
\hline $\begin{array}{l}\text { - health financing } \\
\text { - governance } \\
\text { - health regulations } \\
\text { - health service delivery } \\
\text { - health technology development } \\
\text { - health research ethics } \\
\text { - health information system }\end{array}$ & $\begin{array}{l}\text { - health technology development } \\
\text { - health financing } \\
\text { - health service delivery } \\
\text { - socio-environmental health concerns }\end{array}$ & $\begin{array}{l}\text { - responsive health systems } \\
\text { - research to enhance and extend happy lives } \\
\text { - holistic approaches to health and wellness } \\
\text { - health resiliency } \\
\text { - global competitiveness and innovation in health } \\
\text { - research in equity and health }\end{array}$ \\
\hline
\end{tabular}




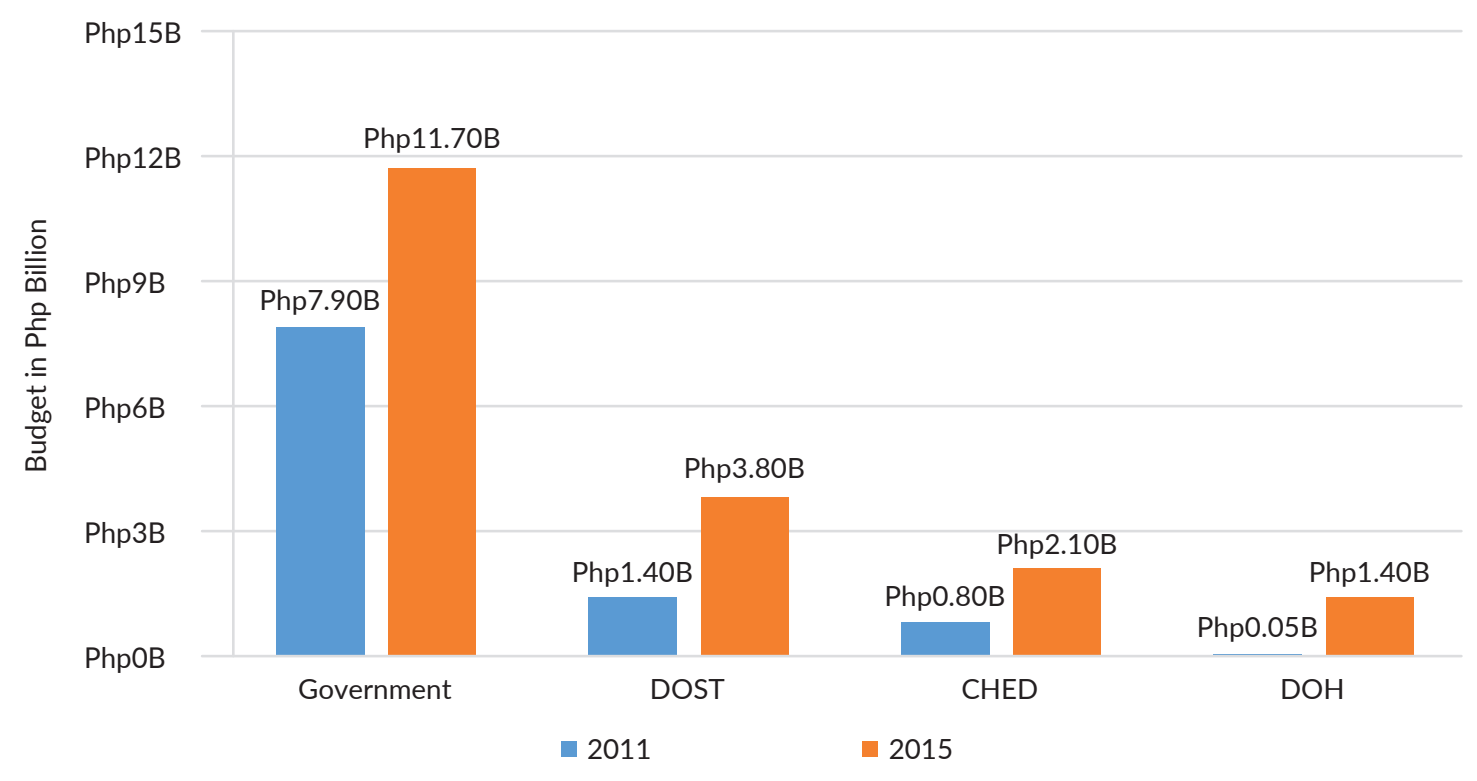

Figure 2. Research and development budget of PH government and selected agencies in 2011 and 2015.

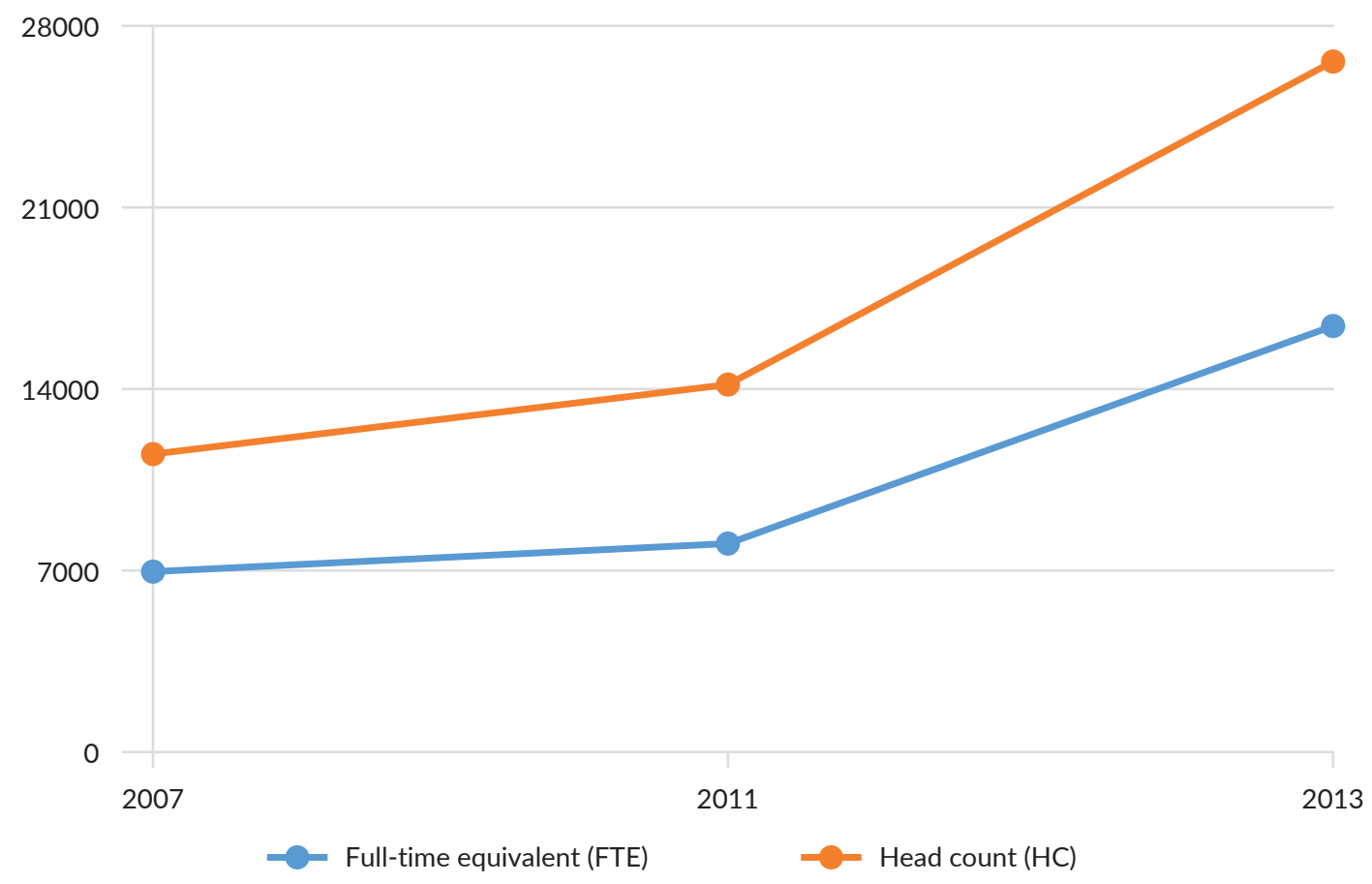

Figure 3. Number of researchers in the Philippines in 2007, 2011, and 2013.

Despite these encouraging trends, starting a research career is still fraught with challenges, which include inadequate funding opportunities for research, lack of mentorship, and insufficient organizational support. ${ }^{18,19}$ While Philippine statistics are still lacking, it may well be inferred that potent driving forces for health professionals to undertake research are tenure and promotion. However, by 2040 , a more enabling environment for health research and researchers is envisioned, due to policies and structures in higher education institutions that increasingly recognize the importance of research-focused faculty, ${ }^{20}$ that include more scholarships and grants to be offered to strengthen human and institutional capacities. Due to the efforts of the Philippine Council for Health Research and Development and the Commission on Higher Education, and the strengthening of the PNHRS, it is expected that by 2040, researchers and research institutions will proliferate in the regions and will not be any more concentrated in NCR. 
The Philippine Health Research System in 2040

More international research centers that will offer training to local and foreign graduates will also be established. Laws for international collaboration will likewise be developed, especially in the background of increasing global collaborations and the emergence of the field of global health.

Thus, given the current trend for financial resources, funding for health research is seen to continuously increase until 2040, majority of which will be coming from the government and we will be less dependent from international funding.

\section{Production}

In 2013, the PNHRS was established to ensure that health research output in the country is aligned with the current needs and opportunities. The PNHRS facilitates development of the NUHRA, which outlines priority researches for a specific period of time. It serves as guide to ensure researches being conducted are relevant and responsive to the current needs of the country. ${ }^{21}$ Evaluation of the NUHRAs showed that uptake of NUHRA 1 was only at $22.7 \%$. Of the 422 health research priorities, only 96 were implemented..$^{22}$ For NUHRA 2, 45 of the 56 (80\%) research priorities were implemented, with 483 total number of studies and PHP 1.5B total funding. ${ }^{19}$ While timeliness is not considered a big problem in terms of production, challenges in procurement have caused delays in outputs.

In 2040, more relevant and timely outputs are envisioned with the enactment of policies that will support smooth research implementation. In ensuring relevance of health researches, strategic implementation of the NUHRA will be crucial. Current policies and guidelines for research implementation, which includes procurement and bidding, will have to be improved to ensure adherence to timelines of research completion.

\section{Packaging}

One of the most common methods of packaging of research outputs is through publication. Based on data from Thomson Reuters, there were 2,318 research papers published in the Philippines from 2009 to 2011, giving the country a rank of 67 th worldwide. ${ }^{13}$ Similar with other countries in Asia, scientific journals in the Philippines face various challenges. Among these challenges are getting listed in the master journal lists and citation databases, obtaining funds, and reaching a wider readership. ${ }^{23}$

While publication may be a good strategy to disseminate research results to a wide set of audience, it only targets a specific group, majority of which are academicians and/or researchers in the same field. Dissemination of research results and information to the public continue to be a challenge. In order to improve uptake, it is important that the message of the research be properly conveyed to people outside the health field.

In 2040, more innovative platforms will be utilized to disseminate research results to all types of audience.Media will assume a more important role, particularly in dissemination to the public. Policy fora will still be utilized for research dissemination to key people involved in policy development. A knowledge broker who will be able to properly convey critical points of a research to maximize the limited time of policymakers and decision makers is also seen to be in place.

\section{Impact}

Impact can be classified as academic or socioeconomic. Academic impact is the intellectual contribution within academia while socioeconomic is the impact of studies beyond academia. ${ }^{24}$ Evidence of academic impact may be based on various bibliometric methods which include publications and citations. Currently, the Philippines ranks 6th in terms of number of papers published and citations among ASEAN countries. Table 2 shows the number of papers and citations of the different ASEAN countries, with the Philippines lagging far behind other ASEAN countries in terms of publications and citations. Socioeconomic impact in terms of influence of research to policy and the society will likewise need to be stepped up. While there are numerous studies being conducted, only a few are translated into policy and thus influence society. This may be due to lack of policies, guidelines, and resources allocated for research translation.

Table 2. Number of papers and citation of the different ASEAN countries ${ }^{11}$

\begin{tabular}{lcc} 
Country & Number of papers & Number of citations \\
Malaysia & 93,406 & 292,001 \\
Singapore & 80,680 & 701,014 \\
Thailand & 53,334 & 257,150 \\
Indonesia & 15,728 & 58,632 \\
Vietnam & 12,696 & 60,540 \\
Philippines & 7,354 & 47,088 \\
Cambodia & 1,064 & 10,905 \\
Brunei & 879 & 2,373 \\
Laos & 750 & 4,237 \\
Myanmar & 558 & 1,651 \\
\hline
\end{tabular}

Improved policies and guidelines for research implementation are envisioned by 2040 to facilitate production of quality outputs that will in turn influence policy and society. More resources are allocated for research translation to improve socioeconomic impact. Academic and socioeconomic impact of researches will not only be seen in the Philippines, but also in the international community.

\section{DISCUSSION}

With the closely intertwined results of each component in the health research profile framework used in presenting the results of this paper, it may be established that in the Philippine context, these components do not necessarily interact in a chain-wise fashion, since these factors affect all others concurrently. To improve the health research system and ensure that the vision by 2040 is realized, efforts must be 
initiated that are oriented towards strengthening knowledge management processes, making knowledge accessible to all stakeholders, contextualizing research output within the political and social context, and facilitating decisions to improve population health and health equity. ${ }^{9,25}$ In addition, knowledge generation through development of health research priorities allow for effective management through efficient allocation of resources. Resources is directly linked with the capacity of health research system and therefore directly affects production. While quality of the research ultimately affects academic and socioeconomic impact, packaging has a major role in conveying results of the research, facilitating translation into health policies and programs, and thus facilitating behavior change in the community. ${ }^{25}$ There is a need therefore to strengthen efforts to bridge the gap between research and action and to improve translation of research into improved health and equity. ${ }^{9,26}$

Nevertheless, there is a need to further explore how research can be carried out in the country for the sake of doing research itself; and for pushing the boundaries of knowledge, by making full use of researchers' academic freedom and creativity, and through sustaining a viable career path for people in the research sector. These may be observed in countries with high human development index, where greater research capacities in terms of resources and production do not necessarily equate to alignment of research with health priorities or use of research for policy development. Because this is not yet the case for the Philippines, currently a lower middle-income country, ${ }^{21}$ the need to prioritize resources to fund and sustain health research is an indication that research has yet to be fully integrated in health program operations and that linking all the components to achieve desired impact continue to be a challenge. ${ }^{9}$ While we are optimistic on the promise held by current developments in health research, as long as there is a lack of driving factors that will increase the attractiveness of a health research career, these visions may be difficult to achieve.

\section{CONCLUSION AND RECOMMENDATIONS}

To ensure that these visions become reality, support from the government will be needed to catalyze social support for research endeavors, and to foster a more enabling environment for health research in the country. While there is an evident increase in funding, financial resources will not be enough to support researchers and research institutions and increase the value of health research. There is a need to improve current policies and guidelines for research implementation, to strengthen capacities of researchers and research institutions, particularly in the regions, and to provide infrastructure (e.g. facilities and equipment) that can support more advanced researches. There has to be a recognition that research is multifactorial and efforts must be made simultaneously to address all factors affecting health research.

Additionally, while the NUHRA outlines research priorities based on current needs of the country, it only serves as a guide for strategic and efficient allocation of resources. Researchers will also need to be forward-thinking and conduct researches anticipating future needs and trends not just in the country but also in the global community to increase the national scientific capital of the Philippines.

Finally, international collaboration will play a big role in advancing health research in our country by providing access to scientific knowledge generated by researchers from other countries and by obtaining innovative technological information and knowledge necessary to be globally competitive. ${ }^{27}$ Laws on international collaboration will, therefore, have to be developed to increase opportunities for international training and collaborative research.

In summary, there have been a lot of improvements and support for heath research in the past years. Thus, to create an enabling health research system in the Philippines by 2040 , focusing on innovations in health research, increase number of funding sources, and crafting of better policies on health research should be pursued. Sustaining these gains and advancing health research in our country entail collective effort from different stakeholders, both public and private.

\section{Statement of Authorship}

All authors approved the final version submitted.

\section{Author Disclosure}

All authors declared no conflicts of interest.

\section{Funding Source}

This paper was funded by the Philippine Council for Health Research and Development.

\section{REFERENCES}

1. National Economic and Development Authority. AmBisyon Natin 2040: A Long-term Vision for the Philippines [Internet]. 2016 [cited 2018 April]. Available from: http://2040.neda.gov.ph/wp-content/ uploads/2016/04/A-Long-Term-Vision-for-the-Philippines.pdf

2. The European Commission - Scientific Panel for Health. Better research for better health: a vision for health and biomedical research from the Scientific Panel for Health [Internet]. 2016 [cited 2018 April]. Available from: http://ec.europa.eu/programmes/horizon2020/ sites/horizon2020/files/SPH_Vision_Paper_27052016.pdf.

3. Murphy K, Topel R. The economic value of medical research. Chicago, IL: University of Chicago Press; 1999.

4. Hatfield M, Sonnenschein HF, Rosenberg LE. Exceptional returns: the economic value of America's investment in medical research [Internet]. 2001 [cited April 2018]. Available from: http://www.laskerfoundation. org/advocacy/pdf/exceptional.pdf

5. Nass SJ, Levit LA, Gostin LO. Institute of Medicine (US) Committee on Health Research and the Privacy of Health Information: The HIPAA Privacy Rule. The Value, Importance, and Oversight of Health Research [Internet]. 2009 [cited 2008 April]. Available from: https:// www.ncbi.nlm.nih.gov/books/NBK9571/. 
6. Sustainable Development. n.d. "What Is Sustainable Development." What Is Sustainable Development - Sustainable Development Commission [Internet]. 2016 [cited 2018 April]. Available from: www. sd-commission.org.uk/pages/what-is-sustainable-development.html.

7. The World Bank. n.d. "Sustainable Development." [Internet] 2016 [cited 2018 April]. Available from: http://www.worldbank.org/en/ topic/sustainabledevelopment.

8. Graneheim UH, Lundman B. Qualitative content analysis in nursing research: concepts, procedures, and measures to achieve trustworthiness. Nurse Educ Today. 2004 Feb; 24(2):105-12.

9. Tugwell P, Sitthi-Amorn C, Hatcher-Roberts J, Neufeld V, Makara P, Munoz F, et al. Health Research Profile to assess the capacity of low- and middle-income countries for equity-oriented research. BMC Public Health 2006 Jun 12; 6:151. doi:10.1186/1471-2458-6-151.

10. World Health Organization. Global Forum for Health Research: global research challenges for oral health [Internet]. $2004 \quad$ [ c i t e d 2018 April]. Available from http://www.who.int/oral_health/ events/global-forum-mexico-2014/en/.

11. World Health Organization. "Databases on Inputs to R\&D." [Internet] 2017 [cited 2018 April]. Available from: https://www.who. int/research-observatory/resources/databases/inputs/en/index2.html.

12. Uis. "UIS Statistics." Education [Internet]. 2018 [cited 2018 April]. Available from: http://www.data.uis.unesco.org/\#.

13. Japan Science and Technology Agency. Current status on science and technology in ASEAN countries [Internet]. 2015 [cited 2018 April]. Available from http://www.jst.go.jp/crds/pdf/en/CRDS-FY2014OR-02_EN.pdf.

14. Department of Science and Technology. DOST gets the highest research and development budget among government institutions [Internet]. 2015 [cited 2018 April]. Available from http://region5. dost.gov.ph/archives/74-dost-gets-the-highest-research-anddevelopment-budget-among-government-institutions.

15. Philippine National Health Research System. National Unified Health Research Agenda 2006-2010 [Internet]. 2006 [cited 2018 April]. Available from: http://www.pchrd.dost.gov.ph/index.php/downloads/ category/4-nuhra\#.

16. Philippine National Health Research System. National Unified Health Research Agenda 2017-2022 [Internet]. 2017 [cited 2018 April]. Available from: http://healthresearch.ph/index.php/nuhra.

17. Neul JL. Interested in a career as a clinician-scientist? Dis Model Mech. 2010 Mar-Apr; 3(3-4):125-30. doi: 10.1242/dmm.005462
18. Kavallaris M, Meachem SJ, Hulett M, et al. Perceptions in health and medical research careers: the Australian Society for Medical Research Workforce survey [Internet]. 2008 [cited 2018 April]. Available from: https://www.mja.com.au/system/files/issues/188_09_050508/ kav11391_fm.pdf.

19. Bloomfield GS, Xavier D, Belis D, Alam D, Davis P, Dorairaj P, et al. Training and capacity building in LMIC for research in heart and lung diseases: the NHLBI-UnitedHealth Global Health Centers of Excellence Program. Glob Heart. 2016 Mar; 11(1):17-25. doi: 10.1016/j.gheart.2016.01.004.

20. Commission on Higher Education. 2016. Pathways to Equity, Relevance and Advancement in Research, Innovation, and Extension in Philippine Higher Education. Commission on Higher Education Memorandum Order no. 52, Series of 2016. 3 October 2016.

21. The World Bank. Lower middle-income countries databank [Internet]. 2018 [cited 2018 June]. Available from: https://data.worldbank.org/ income-level/lower-middle-income.

22. Ramos-Jimenez P, Arguelles M. The Philippine National Health Research System: an assessment of the National Unified Health Research Agenda (2006-2010). Taguig City: Philippine Council on Health Research and Development. 2011.

23. Ramos-Jimenez P, Aragones DC, Mendoza YF, Togonon LD, Yubia MC, Amita GA. Assessment of the 2011-2016 National Unified Health Research Agenda (NUHRA) and the 2011-2015 Regional Unified Health Research Agenda (RUHRA). Taguig City: Philippine Council on Health Research and Development. 2015.

24. Tecson-Mendoza EM. Scientific and academic journals in the Philippines: status and challenges. Sci Ed. 2015; 2(2):73-8.

25. Pang T, Pablos-Mendez A, Ijsselmuiden C: From Bangkok to Mexico: towards a framework for turning knowledge into action to improve health systems. Bull World Health Organ. 2004 Oct; 82(10):720-1.

26. Penfield T, Baker MJ, Scoble R, Wykes MC. Assessment, evaluations, and definitions of research impact: a review. Res Evaluation. 2013; 23(1):21-32.

27. Canadian Institutes of Health Research [Internet]. 2013 [cited 2018 April]. International Collaboration. Available from: http://www.cihrirsc.gc.ca/e/27172.html. 